\title{
Compounds from Olea europaea and Pistacia lentiscus inhibit oral microbial growth
}

${\text { Lamprini Karygianni }{ }^{1 *} \text { D, Manuel Cecere }}^{2}$, Aikaterini Argyropoulou ${ }^{3,4}$, Elmar Hellwig $^{2}$, Alexios Leandros Skaltsounis ${ }^{3}$, Annette Wittmer ${ }^{5}$, Jörg Philipp Tchorz ${ }^{6}$ and Ali Al-Ahmad²

\begin{abstract}
Background: In view of the increasing antibiotic resistance, the introduction of natural anti-infective agents has brought a new era in the treatment of bacterially derived oral diseases.

Methods: The aim of this study was to investigate the antimicrobial potential of five natural constituents of Olea europaea (oleuropein, maslinic acid, hydroxytyrosol, oleocanthal, oleacein) and three compounds of Pistacia lentiscus (24Z-isomasticadienolic acid, oleanolic acid, oleanonic aldehyde) against ten representative oral bacterial species and a Candida albicans strain. After the isolation and quality control of natural compounds, the minimum inhibitory concentration (MIC) and the minimum bactericidal concentration (MBC) assay were performed.

Results: Among all O. europaea-derived constituents, maslinic acid was the most active (MIC $=4.9-312 \mu \mathrm{g} \mathrm{mL}^{-1}$, $\mathrm{MBC}=9.8-25 \mathrm{\mu g} \mathrm{mL}^{-1}$ ) one against oral streptococci and anaerobic pathogenic bacteria (Porphyromonas gingivalis, Fusobacterium nucleatum, Parvimonas micra), while oleuropein, hydroxytyrosol, oleocanthal and oleacein showed milder, yet significant effects against $P$. gingivalis and F. nucleatum. Among all P. lentiscus compounds, oleanolic acid was the most effective one against almost all microorganisms with MIC values ranging from $9.8 \mathrm{\mu g} \mathrm{mL}^{-1}$ ( $P$. gingivalis) to $625 \mathrm{\mu g} \mathrm{mL}^{-1}$ (F. nucleatum, P. micra). In the presence of 24Z-isomasticadienolic acid, a mean inhibitory concentration range of $2.4 \mu \mathrm{g} \mathrm{mL}^{-1}$ to $625 \mathrm{\mu g} \mathrm{mL}^{-1}$ was observed for strict anaerobia. The MIC value for $24 Z$-isomasticadienolic acid was estimated between $39 \mathrm{\mu g} \mathrm{mL}^{-1}$ (Streptococcus sobrinus, Streptococcus oralis) and $78 \mathrm{\mu g} \mathrm{mL}^{-1}$ (Streptococcus mutans). All tested compounds showed no effects against Prevotella intermedia.
\end{abstract}

Conclusions: Overall, maslinic acid and oleanolic acid exerted the most significant inhibitory activity against the tested oral pathogens, especially streptococci and anaerobic oral microorganisms.

Keywords: Natural compounds, Olea europaea, Pistacia lentiscus, Oral microorganisms, Minimum inhibitory concentration (MIC), Minimum bactericidal concentration (MBC)

\section{Background}

The nature-inspired therapies of various bacterially-driven infections based on herbals are one of the most current therapeutic trends in medicine [1]. Nevertheless, more than 300.000 plant extracts need to be screened for their antioxidant and antimicrobial properties [2-4]. Among these, a selection of Mediterranean plant extracts from olive (Olea europaea), parsley (Petroselinum crispum),

\footnotetext{
* Correspondence: lamprini.karygianni@zzm.uzh.ch

${ }^{1}$ Clinic for Preventive Dentistry, Periodontology and Cariology, Center of

Dental Medicine, University of Zurich, Zürich, Switzerland

Full list of author information is available at the end of the article
}

oregano (Origanum vulgare), thyme (Thymus vulgaris), sage (Salvia officinalis), mastic gum (Pistacia lentiscus) and false yellowhead (Inula viscosa) have shown a significant inhibitory activity against numerous bacteria [5-7]. However, to elucidate the mechanisms relating to their complex biological behavior, the effect of pure plant-derived compounds on microorganisms has to be investigated $[8,9]$.

The antimicrobial traits of plants can be attributed to the activity of natural antibiotics with low molecular weight $(\mathrm{MW}<500)$, named phytoalexins, and synergistic action $[10,11]$. These well-studied antimicrobial

(c) The Author(s). 2019 Open Access This article is distributed under the terms of the Creative Commons Attribution 4.0 International License (http://creativecommons.org/licenses/by/4.0/) which permits unrestricted use, distribution, and reproduction in any medium, provided you give appropriate credit to the original author(s) and the source, provide a link to the Creative Commons license, and indicate if changes were made. The Creative Commons Public Domain Dedication waiver (http://creativecommons.org/publicdomain/zero/1.0/) applies to the data made available in this article, unless otherwise stated. 
stress-derived metabolites of plant origin include flavonoids, glycosteroids, terpenoids, and polyphenols [12]. Furthermore, other specific defense mechanisms of plants are supported by the release of avirulence (Avr) gene-activated resistance $(\mathrm{R})$ proteins or the secretion of a polysaccharide with (1-3)- $ß-D$-glucan subunits, namely callose, under the threat of the microbial invaders [13, 14]. Finally, plants produce endogenous antimicrobial peptides with less than 100 amino acid residues, low acquisition of resistance and broad-spectrum antimicrobial features [15].

Surprisingly, trillions of microbes are an integral part of the healthy human body and outnumber host cells by 10 to 1 [16]. Although microbes could benefit humans by carrying 8 million health-related genes, they are also able to turn into pathogenic body inhabitants under specific circumstances $[17,18]$. The high pathogenicity of bacteria, viruses, and fungi can be demonstrated through the formation of antibiotic-resistant oral biofilms [19]. The oral cavity is a representative ecological niche with more than 700 microbial residents, often organized in biofilm networks on teeth or gingiva [20]. As a result, biofilm-associated oral diseases such as caries, gingivitis or periodontitis can occur [21].

In recent years the research on the chemotherapeutic intransigence of microbial biofilms, whose antibiotic resistance is 1000 times higher compared to planktonic bacterial cells, has been intensified [22]. In the oral cavity in particular, the antibiotic-resistant Enterococcus faecalis detected in infected root canals expressed the endocarditis-related antigen A $(E f a A)$ [23]. Due to the production of $\beta$-lactamases by Prevotella spp., fusobacteria and capnocytophaga, an abundance of ${ }^{b l a}$ TEM resistance genes could be identified in subgingival and tongue samples [24]. Therefore, there is an urgent need for novel oral antimicrobials with low risk of provoking bacterial resistance to antibiotic monotherapy [3]. In that context, the scenario of introducing novel phytopharmaceuticals has attracted attention lately [25, 26]. The effectiveness of natural antimicrobial candidates can be attributed to their synergistic impact and broad pharmaceutical spectrum resulting from secondary metabolic reactions $[27,28]$.

For this purpose, the present report focused on the antimicrobial behavior of natural compounds deriving from Olea europaea L. (Oleaceae) and Pistacia lentiscus L. (Anacardiaceae) against representative oral bacterial species. More specifically, eight different antimicrobial agents from olive leaves, table olive processing wastewater, olive oil and mastic gum were screened against eight representative bacterial inhabitants of the oral cavity, namely Streptococcus mutans, Streptococcus sobrinus, Streptococcus oralis, Enterococcus faecalis, Porphyromonas gingivalis, Parvimonas micra, Prevotella intermedia,
Fusobacterium nucleatum and the yeast Candida albicans. Among these S. mutans and S. sobrinus are related to dental caries [29], E. faecalis correlates with secondary endodontic infections [30], $P$. gingivalis, $P$. micra and $P$. intermedia are periodontal pathogens [31], while C. albicans can cause oral infections in denture wearers [32].Typical representatives of the intestinal and skin flora such as Escherichia coli and Staphylococcus aureus, respectively, were used as reference bacteria. In our previous report, an olive extract and total mastic extract from $P$. lentiscus exhibited significant antimicrobial activity against oral microorganisms [33]. The null hypothesis of this report was that the tested natural compounds from $O$. europaea and P. lentiscus have no antimicrobial effect on oral microbes. To assess this, two antimicrobial assays - the minimum bactericidal concentration $(\mathrm{MBC})$ and the minimum inhibitory concentration (MIC) assay were applied.

\section{Methods}

Following our research on the antimicrobial efficacy of Mediterranean natural plant extracts, some of the most promising extracts were selected [33] and their major compounds were tested.

\section{Compounds extraction from 0 . europaea}

Oleuropein and maslinic acid used in this study were isolated from an extract deriving from O. europaea $\mathrm{L}$. (Oleaceae) leaves that were collected in 2009 at the region of Attica and were identified by Dr. E. Kalpoutzakis. A voucher specimen is deposited at the herbarium of the Department of Pharmacognosy and Natural Products Chemistry, Faculty of Pharmacy, University of Athens, Greece under the number PROK 006. The preparation of the extract has been described in a previous report [33]. The extract $(360 \mathrm{~g})$ was separated, dried and subjected to medium pressure Liquid Chromatography (MPLC) with silica (Si) gel 60 Merck (15-40 mm), using the dichloromethane $\left(\mathrm{CH}_{2} \mathrm{Cl}_{2}\right)$ / methanol $(\mathrm{MeOH})$ gradient as the eluent to extract pure oleuropein $(\geq 95 \%)$ and maslinic acid ( $\geq 95 \%$ ). Hydroxytyrosol was isolated from an extract produced from table olive processing wastewater. The preparation of the extract and the isolation of pure hydroxytyrosol $(\geq 95 \%)$ have been previously described [34]. For the procurement of oleacein and oleocanthal the total polyphenol fraction (TPF) of extra virgin olive oil (EVOO) was used as starting material [35], while for their isolation column chromatography (CC) and preparative Thin Layer Chromatography (TLC) were employed, as previously described [36]. Briefly, $170 \mathrm{~L}$ of EVOO was subjected to $25 \mathrm{~kg}$ of the adsorbent XAD-7HP resin. The resin was activated with water $\left(\mathrm{H}_{2} \mathrm{O}\right)$ and ethanol $(\mathrm{EtOH})$, and EVOO remained in the XAD-7HP resin for 2 days with controlled and 
smoothed shaking and filtered. The resin was washed with $30 \mathrm{~L}$ cyclohexane (cHex) for the removal of the lipophilic constituents, and then the polyphenol-enriched extract was obtained by the extraction of the resin with approx. $40 \mathrm{~L}$ of ethanol. Further purification was achieved by liquid-liquid extraction using $\mathrm{cHex}$ and $\mathrm{EtOH}$, and the obtained ethanolic fraction was filtered through paper and evaporated until dry affording $150 \mathrm{~g}$ of TPF. In continuation, $250 \mathrm{mg}$ of TPF were subjected to a Si gel (0.015$0.04 \mathrm{~mm})$ column $(25 \times 2.7 \mathrm{~cm})$ and mixtures of $\mathrm{CH}_{2} \mathrm{Cl}_{2}$ and $\mathrm{MeOH}$ in increasing polarity $(0-10 \% \mathrm{MeOH})$ were used for the elution. From the fractions obtained using 98:2 $\mathrm{CH}_{2} \mathrm{Cl}_{2} / \mathrm{MeOH}$, oleocanthal was isolated, while from the fractions obtained using 97:3 $\mathrm{CH}_{2} \mathrm{Cl}_{2} / \mathrm{MeOH}$, oleacein was attained. For further purification, preparative TLC was used. Specifically, precoated TLC silica 60 F254 plates, $2 \mathrm{~mm}$ layer thickness (purchased from Aldrich), were used while 94:6 $\mathrm{CH}_{2} \mathrm{Cl}_{2} / \mathrm{MeOH}$ was used as the mobile phase. Spots were visualized using ultraviolet (UV) light and vanillin-sulfuric acid reagent. Finally, oleocanthal $(\geq 95 \%)$ and oleacein $(\geq 95 \%)$ were purified.

\section{Compounds extraction from $P$. lentiscus}

24Z-isomasticadienolic acid, oleanolic acid and oleanonic aldehyde were isolated from mastic gum [37]. Commercially available mastic gum was supplied by Chios Mastic Growers Association which is the exclusive worldwide producer of the resin. Conventional extraction of mastic gum for the preparation of total mastic extract without polymer (TMEWP) (extraction A) has been described in a previous report (Karygianni et al., 2014a). TMEWP partitioned between aqueous 5\% $\mathrm{Na}_{2} \mathrm{CO}_{3}$ and ether as already described (extraction $\mathrm{B}$ ) [38]. The organic phase was reextracted three times with $5 \% \mathrm{Na}_{2} \mathrm{CO}_{3}$ (extraction $\mathrm{C}$ ) and afforded the neutral fraction of mastic $(135 \mathrm{~g})$ as the organic phase. The aqueous phase was added to that of extraction $\mathrm{B}$ and acidified with $1 \mathrm{~N} \mathrm{HCl}$. The acidic solution was reextracted with ether (extraction D), and the organic phase afforded the acid fraction of mastic $(190 \mathrm{~g})$.

The acidic fraction ( $20 \mathrm{~g}$ ) was submitted to MPLC over normal-phase silica gel first with a cHex / $\mathrm{CH}_{2} \mathrm{Cl}_{2}$ gradient and then with a $\mathrm{CH}_{2} \mathrm{Cl}_{2} / \mathrm{MeOH}$ gradient affording 23 fractions. In continuation, oleanolic acid was separated by MPLC over normal-phase silica gel eluted with a $\mathrm{CH}_{2} \mathrm{Cl}_{2}$ / $\mathrm{MeOH}$ gradient, while 24Z-isomasticadienolic acid by column chromatography over silica gel eluted with a $\mathrm{CH}_{2} \mathrm{Cl}_{2} / \mathrm{MeOH}$ gradient. A part of the neutral fraction (17.2 g) was submitted to column liquid chromatography over normal-phase silica gel with a cHex $/ \mathrm{CH}_{2} \mathrm{Cl}_{2}$ gradient to afford 22 fractions. Oleanonic aldehyde was separated in continuation by MPLC over normal-phase silica gel eluted with a cHex $/ \mathrm{CH}_{2} \mathrm{Cl}_{2}$ gradient.

\section{Chemical analysis of compounds}

The chemical structures of the tested compounds are demonstrated on Fig. 1 . The identity and purity $(\geq 95 \%)$ of the isolated compounds were confirmed by nuclear magnetic resonance spectroscopy (NMR), mass spectrometry (MS) and high performance liquid chromatography (HPLC) experiments and by comparison with literature data. All solvents (ethanol, methanol, dichloromethane and cyclohexane) were of p.A. quality and came from Merck (Darmstadt, Germany). Water was purified by double distillation.

\section{Bacterial strains and Candida albicans}

A total of eleven microbial strains from ten different bacterial strains and one Candida albicans strain were tested. Among these eight bacterial strains and C. albicans represent typical oral inhabitants, while the reference bacterial strains Escherichia coli and Staphylococcus aureus are members of the intestinal and skin flora, respectively. Their use facilitated the comparison of the antimicrobial activity of the natural compounds within the oral cavity against their general inhibitory impact. Facultative anaerobic Gram-positive species such as Streptococcus mutans DSM 20523, Streptococcus sobrinus DSM 20381, Streptococcus oralis ATCC 35037, Enterococcus faecalis ATCC 29212 and S. aureus ATCC 25923 were tested. Escherichia coli ATCC 25922 served also as a facultative anaerobic bacterium but with a Gram-negative cell wall. The tested obligate anaerobes included Porphyromonas gingivalis W381, Prevotella intermedia ATCC 25611, Fusobacterium nucleatum ATCC 25586 and Parvimonas micra ATCC 23195. All bacterial strains and C. albicans were kindly provided by the Division of Infectious Diseases and the Institute of Medical Microbiology and Hygiene of the Albert-Ludwigs-University, Freiburg. The microorganisms were kept at $-80{ }^{\circ} \mathrm{C}$ in basic growth medium containing $15 \%(\mathrm{v} / \mathrm{v})$ glycerol prior to use.

\section{Determination of the minimum inhibitory concentration (MIC)}

As described in the Clinical and Laboratory Standards Institute (CLSI) guidelines an overnight culture of each bacterial strain and $C$. albicans was prepared and each dilution was placed on Columbia blood agar plates (CBA, Becton Dickinson GmbH, Heidelberg, Germany) or yeast-cysteine blood agar plates (HCB, Becton Dickinson GmbH, Heidelberg, Germany) [39, 40]. CBA agar plates were used for the incubation of facultative anaerobic bacteria and C. albicans at $37^{\circ} \mathrm{C}$ and $5-10 \% \mathrm{CO}_{2}$ atmosphere for $24 \mathrm{~h}$. HCB agar plates were used for the incubation of anaerobic bacteria at $37^{\circ} \mathrm{C}$ for $48 \mathrm{~h}$ (anaerobic chamber, Genbox BioMérieux SA, Marcy/Etoile, France). For the microdilution assay at $10^{6}$ colony forming units (CFU) $\mathrm{mL}^{-1}$ for each strain, Mueller-Hinton Broth (MHB) was 


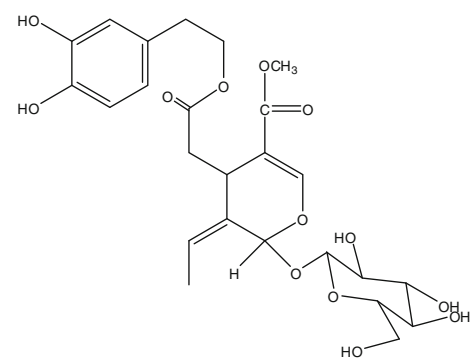

oleuropein<smiles>OCCc1ccc(O)c(O)c1</smiles>

hydroxytyrosol

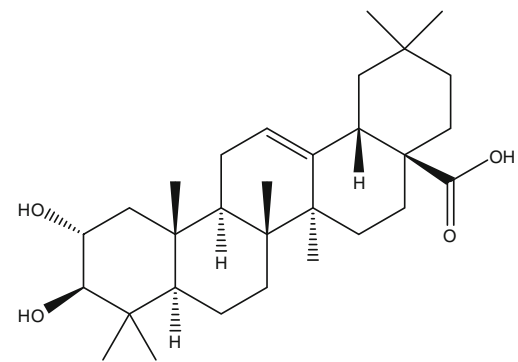

maslinic acid<smiles>C/C=C(/C=O)[C@H](CC=O)CC(=O)OCCc1ccc(O)cc1</smiles>

oleocanthal<smiles>C/C=C(/C=O)[C@H](CC=O)CC(=O)OCCc1ccc(O)c(O)c1</smiles>

oleacein

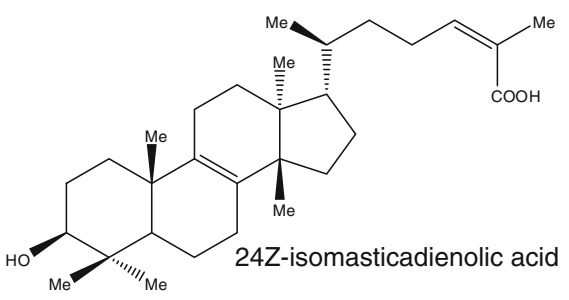<smiles>CC1(C)CC[C@]2(O)CC[C@]3(C)C(=CCC4[C@@]5(C)CC[C@@H](O)C(C)(C)C5CC[C@]43C)C2C1</smiles><smiles>CC1(C)CC[C@@]2(C=O)CC[C@]3(C)C(=CCC4[C@@]5(C)CCC(=O)C(C)(C)C5CC[C@]43C)C2C1</smiles>

Fig. 1 Chemical structures of the tested compounds from Olea europaea (oleuropein, maslinic acid, hydroxytyrosol, oleocanthal, oleacein) and Pistacia lentiscus (24Z-isomasticadienolic acid, oleanolic acid, oleanonic aldehyde)

utilized for the inoculation of all facultative anaerobic strains, Wilkins-Chalgren broth (WCB) for anaerobic bacteria and Sabouraud Dextrose Broth (SDB) for C. albicans. Then, with the aid of a multi-channel pipette appropriate volumes of the MHB/WCB/SDB microbial cultures were transferred into a 96-well microtiter-plate. Each well of the 96-well microtiter-plate had a total volume of $200 \mu \mathrm{L}$. Afterwards the prepared compounds were dissolved in dimethyl sulfoxide (DMSO, Sigma, Steinheim, Germany) and diluted in distilled water. A concentration series ranging from $2500 \mu \mathrm{g} \mathrm{mL}^{-1}$ to $2.4 \mu \mathrm{g} \mathrm{mL}^{-1}$ at dilution levels starting from 2 -fold to 512 -fold was used to screen all compound solutions in DMSO. The experiments were conducted in duplicate. For bacteria and fungi, a $0.5 / 1 \mathrm{~A}$ McFarland standard suspension was diluted in normal saline. A dilution series of DMSO was tested in parallel in order to exclude potential inhibitory effects of the DMSO residuals. In case of bacterial growth in the co-tested DMSO dilution series the inhibitory impact of DMSO was taken into account. Wells containing 
only sterile $\mathrm{MHB} / \mathrm{WCB} / \mathrm{SDB}$ to minimize the possibility of contamination or $0.2 \%$ chlorhexidine (CHX) served as positive and negative controls, respectively. Thereafter, facultative anaerobic bacteria and C. albicans were incubated at $37^{\circ} \mathrm{C}$ and $5-10 \% \mathrm{CO}_{2}$ atmosphere for $24 \mathrm{~h}$, while anaerobic bacteria were kept at $37^{\circ} \mathrm{C}$ for $48 \mathrm{~h}$ (anaerobic chamber, Genbox BioMérieux SA, Marcy / Etoile, France). All assays for each bacterial strain and C. albicans were conducted in duplicate. If the MIC values of a specific strain were not identical, the highest minimum inhibitory concentration (MIC) values were taken into account. MIC was determined as the lowest concentration of each compound at which visible inhibition of bacterial growth occurred, and was expressed by the percentage of bacterial growth at that particular concentration.

\section{Determination of the minimum bactericidal concentration (MBC)}

As described in the CLSI guidelines the minimum bactericidal concentration (MBC) could also be determined $[39,40]$. After the MIC testing, $10 \mu \mathrm{L}$ from each well of the 96-well microtiter-plates containing the tested compound concentration series were incubated on agar plates. In particular, Columbia blood agar (CBA) agar plates were used for facultative anaerobic bacteria and $C$. albicans at $37^{\circ} \mathrm{C}$ and $5-10 \% \mathrm{CO}_{2}$ atmosphere for 2 days. Strictly anaerobic bacteria were incubated on yeast-cysteine blood agar ( $\mathrm{HCB})$ plates at $37^{\circ} \mathrm{C}$ for 5 days (anaerobic chamber, Genbox BioMérieux SA, Marcy/Etoile, France). The colony forming units (CFU) were determined visually. The MBC was determined as the concentration at which a three-log decrease in bacterial growth $(=99.9 \%)$ was detected compared to the positive control. In the presence of variations within the yielded MIC/MBC values after the repetition of the experiments, the highest $\mathrm{MIC} / \mathrm{MBC}$ values were listed to eliminate false positive results.

\section{Results}

\section{O. europaea}

Five compounds (oleuropein, maslinic acid, hydroxytyrosol, oleocanthal and, oleacein) isolated from O. europaea by-products (leaves, table olives processing wastewater) and products (olive oil) were screened. Table 1 demonstrates the mean MIC and MBC values for each of the aforementioned $O$. europaea compounds as well as the tested bacterial and fungal strains.

Overall, maslinic acid was more effective than oleuropein, hydroxytyrosol, oleocanthal and oleacein. Maslinic acid was active against almost all anaerobic bacterial strains, with a mean concentration range of $4.9 \mu \mathrm{g} \mathrm{mL}^{-1}$ (Porphyromonas gingivalis) to $312 \mu \mathrm{g} \mathrm{mL}^{-1}$ (Fusobacterium nucleatum). The obligate anaerobe Parvimonas micra $\left(9.8 \mu \mathrm{g} \mathrm{mL}^{-1}\right)$ were efficiently inhibited, whereas maslinic acid showed no inhibitory effect against Prevotella intermedia. For streptococci (Streptococcus mutans, Streptococcus sobrinus, Streptococcus oralis) the MIC value for maslinic acid was estimated at $19.5 \mu \mathrm{g} \mathrm{mL}{ }^{-1}$, for Enterococcus faecalis at $39 \mu \mathrm{g} \mathrm{m}^{-1}$, for Staphylococcous aureus at $78 \mu \mathrm{g} \mathrm{mL}^{-1}$. The highest MIC value at $1.25 \mathrm{mg} \mathrm{mL}^{-1}$ was detected for Escherichia coli and Candida albicans. For obligate anaerobes, maslinic acid showed low MBC values, which ranged from $9.8 \mu \mathrm{g} \mathrm{mL}^{-1}$ (P gingivalis, $P$. micra) to $25 \mu \mathrm{g} \mathrm{mL}^{-1}$ (F. nucleatum). Streptococci such as S. sobrinus and $S$. oralis $\left(19.5 \mu \mathrm{g} \mathrm{mL}^{-1}\right)$ as well as $S$. mutans $\left(156 \mu \mathrm{g} \mathrm{mL}^{-1}\right)$ were more easily eradicated when

Table 1 Antimicrobial activity in $\mu \mathrm{g} \mathrm{mL}^{-1}$ of compounds from O. europaea

\begin{tabular}{|c|c|c|c|c|c|c|c|c|c|c|c|c|}
\hline \multicolumn{13}{|l|}{ O. europaea } \\
\hline \multirow{2}{*}{$\begin{array}{l}\text { Sample (\% dilution in DMSO) } \\
\mathrm{c} / \mu \mathrm{g} \mathrm{mL} \mathrm{L}^{-1}\end{array}$} & \multicolumn{2}{|c|}{$\begin{array}{l}\text { oleuropein } \\
(1.8 \%)\end{array}$} & \multicolumn{2}{|c|}{$\begin{array}{l}\text { hydroxytyrosol } \\
(1.25 \%)\end{array}$} & \multicolumn{2}{|c|}{$\begin{array}{l}\text { oleocanthal } \\
(2.1 \%)\end{array}$} & \multicolumn{2}{|c|}{ oleacein (1.1\%) } & \multicolumn{2}{|c|}{$\begin{array}{l}\text { maslinic acid } \\
(6.6 \%)\end{array}$} & \multicolumn{2}{|c|}{ DMSO in \% } \\
\hline & $\mathrm{MIC}^{\mathrm{a}}$ & $\mathrm{MBC}^{\mathrm{b}}$ & $\overline{\mathrm{MIC}}$ & $\mathrm{MBC}$ & MIC & $\mathrm{MBC}$ & $\overline{M I C}$ & $\mathrm{MBC}$ & MIC & MBC & $\overline{M I C}$ & $M B C$ \\
\hline Streptococcus mutans DSM 20523 & 625 & 625 & 312 & 312 & 1250 & 1250 & 1250 & 1250 & 19.5 & 156 & 6.00 & 25.00 \\
\hline Streptococcus sobrinus DSM 20381 & 625 & 1250 & 625 & 1250 & 312 & 1250 & 1250 & 1250 & 19.5 & 19.5 & 10.00 & 15.00 \\
\hline Streptococcus oralis ATCC 35037 & 1250 & 1250 & 1250 & 1250 & 1250 & 1250 & 1250 & 1250 & 19.5 & 19.5 & 10.00 & 10.00 \\
\hline Enterococcus faecalis ATCC 29212 & 1250 & 1250 & 1250 & 2500 & 1250 & 1250 & 1250 & 1250 & 39 & 312 & 15.00 & 25.00 \\
\hline Candida albicans DSM 1386 & 1250 & 1250 & 1250 & 2500 & 625 & 1250 & 1250 & 1250 & 1250 & 1250 & 8.00 & 8.00 \\
\hline Escherichia coli ATCC 25922 & 1250 & 1250 & 1250 & 2500 & 1250 & 1250 & 1250 & 1250 & 1250 & 1250 & 10.00 & 10.00 \\
\hline Staphylococcus aureus ATCC 25923 & 625 & 625 & 312 & 312 & 1250 & 1250 & 625 & 625 & 78 & 625 & 10.00 & 25.00 \\
\hline Porphyromonas gingivalis W381 & 625 & 625 & 156 & 312 & 156 & 312 & 312 & 625 & 4.9 & 9.8 & 12.5 & 12.5 \\
\hline Prevotella intermedia ATCC 25611 & NA & NA & $312(5 d)$ & NA & NA & NA & $625(5 d) N A$ & & NA & NA & $3.12(5 d)$ & 3.12 \\
\hline Fusobacterium nucleatum ATCC 25586 & 625 & 312 & 312 & 312 & 312 & 312 & 156 & 156 & 312 & 25 & 6.25 & 6.25 \\
\hline Parvimonas micra ATCC 23195 & 1250 & 1250 & 1250 & 1250 & 312 & 312 & 1250 & 1250 & 9.8 & 9.8 & $6.25(5 d)$ & 12.5 \\
\hline
\end{tabular}

NA No activity observed: MIC or MBC were measured at $2500 \mu \mathrm{g} \mathrm{mL}^{-1}, 5 \mathrm{~d}=$ values yielded after 5 days of incubation, ${ }^{\mathrm{a}} \mathrm{MIC}=$ extract concentration at which the optical density (OD) measurement revealed minimal bacterial growth, ${ }^{\mathrm{b}} \mathrm{MBC}=$ extract concentration at which a three log reduction ( $\left.99.9 \%\right)$ of the bacterial growth was induced 
compared to facultative anaerobic E. faecalis $\left(312 \mu \mathrm{g} \mathrm{mL} \mathrm{m}^{-1}\right)$ and $S$. aureus $\left(625 \mu \mathrm{g} \mathrm{mL}^{-1}\right)$. The highest $\mathrm{MBC}$ value at $1.25 \mathrm{mg} \mathrm{mL}^{-1}$ was detected for E. coli and C. albicans, while $P$. intermedia was not affected at all by maslinic acid.

Oleacein exhibited a milder inhibitory activity against oral microorganisms. The lowest MIC values of oleacein were observed for obligate anaerobes and were between $156 \mu \mathrm{g} \mathrm{mL}^{-1}$ (F. nucleatum) and $1.25 \mathrm{mg} \mathrm{mL}^{-1}$ (P. micra). The anaerobic $P$. gingivalis showed also a satisfactory MIC value of $312 \mu \mathrm{g} \mathrm{mL}^{-1}$ and $P$. intermedia could be inhibited only by oleacein $\left(625 \mu \mathrm{g} \mathrm{mL}^{-1}\right)$ after 5 days of culture. All other bacterial strains (streptococci, E. faecalis, E. coli) and C. albicans had MIC and MBC values of $1.25 \mathrm{mg}$ $\mathrm{mL}^{-1}$. The $\mathrm{MBC}$ values of oleacein for obligate anaerobia were substantially lower ranging from $156 \mu \mathrm{g}$ $\mathrm{mL}^{-1}$ (F. nucleatum), $625 \mu \mathrm{g} \mathrm{mL}^{-1}$ (P. gingivalis) to $1.25 \mathrm{mg} \mathrm{mL}^{-1}$ (P. micra).

Oleocanthal also showed an inhibitory effect on oral bacteria. The lowest MIC values of oleocanthal were detected for S. sobrinus $\left(312 \mu \mathrm{g} \mathrm{mL}^{-1}\right)$ as well as obligate anaerobes and varied between $156 \mu \mathrm{g} \mathrm{mL}^{-1}$ ( $P$. gingivalis) and $312 \mu \mathrm{g} \mathrm{mL}^{-1}$ (F. nucleatum, P. micra). C. albicans was eradicated at $625 \mathrm{gg} \mathrm{mL}^{-1}$, whereas the streptococci and reference strains had MIC and MBC values of $1.25 \mathrm{mg} \mathrm{mL}^{-1}$. Obligate anaerobes (P. gingivalis, F. nucleatum, P. micra) showed the lowest MBC value $\left(312 \mu \mathrm{g} \mathrm{mL}^{-1}\right)$, while $P$. intermedia did not respond to the treatment with oleocanthal.

Concerning hydroxytyrosol, the lowest compound concentrations of $156 \mu \mathrm{g} \mathrm{mL}^{-1}$ (P. gingivalis), $312 \mu \mathrm{g}$ $\mathrm{mL}^{-1}$ after 5 days of culture (P. intermedia, F. nucleatum) exerted bactericidal effect mainly on strict anaerobic, Gram-negative bacteria. From the streptococci, $S$. mutans and $S$. sobrinus presented also satisfactory inhibitory values of $312 \mu \mathrm{g} \mathrm{mL}^{-1}$ and $625 \mu \mathrm{g} \mathrm{mL}^{-1}$, respectively. The highest MIC value of hydroxytyrosol $\left(1.25 \mathrm{mg} \mathrm{mL}^{-1}\right)$ was observed for the reference strains, C. albicans. E. faecalis and P. micra. The lowest MBC value of hydroxytyrosol was estimated at $312 \mu \mathrm{g} \mathrm{mL}^{-1}$ (P. gingivalis, F. nucleatum, S. mutans), while $99.9 \%$ of E. faecalis, S. aureus and C. albicans were eradicated by $2.5 \mathrm{mg} \mathrm{mL}^{-1}$ of hydroxytyrosol.

Finally, oleuropein had the mildest antimicrobial impact on the oral pathogens. The MIC and MBC values of the eradicated microbial strains for oleuropein were between $625 \mu \mathrm{g} \mathrm{mL}^{-1}$ (S. mutans, S. aureus, P. gingivalis) to $1.25 \mathrm{mg} \mathrm{mL}^{-1}$ (S. oralis. E. faecalis, E. coli, P. micra, C. albicans). The lowest MBC value of oleuropein $\left(312 \mu \mathrm{g} \mathrm{mL}^{-1}\right)$ was observed for F. nucleatum, whereas $P$. intermedia was not inhibited by this compound.

\section{$P$. lentiscus}

Table 2 summarizes the MIC and MBC values of the three compounds (24Z-isomasticadienolic acid, oleanolic acid, and oleanonic aldehyde) isolated from P. lentiscus for all screened microbial strains.

Among all mastic gum compounds, oleanolic acid was the most effective against almost all microorganisms with MIC values ranging from $9.8 \mu \mathrm{g} \mathrm{mL}^{-1}$ (P. gingivalis) to $625 \mu \mathrm{g} \mathrm{mL}^{-1}$ (F. nucleatum, P. micra) for obligate anaerobes. The MIC value for maslinic acid was estimated at $19.5 \mu \mathrm{g} \mathrm{mL}^{-1}$ for streptococci (S. mutans, S. sobrinus, S. oralis), at $78 \mu \mathrm{g} \mathrm{mL}^{-1}$ for E. faecalis and S. aureus. The highest MIC and MBC value of oleanolic acid (1.25 $\mathrm{mg} \mathrm{mL}^{-1}$ ) was detected for E. coli and C. albicans, whereas $P$. intermedia was not affected at all by oleanolic acid. The mean $\mathrm{MBC}$ values for strict anaerobic bacteria were $9.8 \mu \mathrm{g} \mathrm{mL}^{-1}$ (P. gingivalis), $625 \mu \mathrm{g} \mathrm{mL}^{-1}$ (F. nucleatum) and $1.25 \mathrm{mg} \mathrm{mL}^{-1}$ (P. micra), whereas higher $\mathrm{MBC}$ values were estimated for streptococci at $39 \mu \mathrm{g} \mathrm{mL}^{-1}$ (S. mutans, S. sobrinus) and $78 \mu \mathrm{g} \mathrm{mL}^{-1}$ (S. oralis).

Another compound, the 24Z-isomasticadienolic acid also presented a substantial antimicrobial effect against the screened microorganisms. In its presence, a mean inhibitory concentration range of $2.4 \mu \mathrm{g} \mathrm{mL}^{-1}$ ( $P$. gingivalis, $P$. micra) to $625 \mu \mathrm{g} \mathrm{m}^{-1}$ (F. nucleatum) was observed for strict anaerobia. The MIC value for 24Z-isomasticadienolic acid was estimated between $39 \mu \mathrm{gL}^{-1}$ (S. sobrinus, S. oralis) and $78 \mu \mathrm{g} \mathrm{mL}^{-1}$ (S. mutans) for streptococci, while E. faecalis had a MIC value of $156 \mu \mathrm{g} \mathrm{mL}^{-1}$. The highest MIC and MBC value of $24 Z$-isomasticadienolic acid $\left(1.25 \mathrm{mg} \mathrm{mL}^{-1}\right)$ was detected for E. coli, S. aureus and C. albicans, whereas $P$. intermedia did not respond to the treatment. The lowest MBC value $\left(9.8 \mu \mathrm{g} \mathrm{mL}^{-1}\right)$ were determined for the obligate anaerobia $P$. gingivalis and $P$. micra, while $78 \mu \mathrm{g}$ $\mathrm{mL}^{-1}$ and $156 \mu \mathrm{g} \mathrm{mL}^{-1}$ of the compound killed $99.9 \%$ of $S$. oralis and P. micra and S. mutans, respectively.

Oleanonic aldehyde presented the lowest antimicrobial activity compared to the other two mastic gum compounds. The lowest MIC value of $625 \mu \mathrm{g} \mathrm{mL}^{-1}$ was found for $P$. gingivalis, whereas all other tested bacterial and fungal strains presented $\mathrm{MIC}$ and $\mathrm{MBC}$ value of $1.25 \mathrm{mg} \mathrm{mL}^{-1}$. Oleanonic aldehyde proved to be ineffective against $P$. intermedia.

\section{Discussion}

The present report introduced and screened eight antimicrobial compounds originating from $O$. europaea and $P$. lentiscus against nine representative oral pathogens. The efficacy of three different extracts from the aforementioned plants against oral microorganisms was highlighted in a previous own study [33]. To the best of our knowledge, this is the first study on the inhibition of oral microbial growth induced by the antimicrobial agents of $O$. europaea and P. lentiscus.

In this study, maslinic acid isolated from leaves of $O$. europaea proved to be highly effective, even in very low 
Table 2 Antimicrobial activity in $\mu \mathrm{g} \mathrm{mL}^{-1}$ of compounds from $P$. lentiscus

\begin{tabular}{|c|c|c|c|c|c|c|c|c|}
\hline \multicolumn{9}{|l|}{ P. lentiscus } \\
\hline \multirow{2}{*}{$\begin{array}{l}\text { Sample (\% dilution in DMSO) } \\
\mathrm{c} / \mu \mathrm{g} \mathrm{mL} \mathrm{L}^{-1}\end{array}$} & \multicolumn{2}{|c|}{$\begin{array}{l}\text { 24Z-isomasticadienolic } \\
\text { acid (3.9\%) }\end{array}$} & \multicolumn{2}{|c|}{ oleanolic acid (2.6\%) } & \multicolumn{2}{|c|}{ oleanonic aldehyde (2.4\%) } & \multicolumn{2}{|c|}{ DMSO (in \%) } \\
\hline & $\mathrm{MIC}^{\mathrm{a}}$ & $\mathrm{MBC}^{\mathrm{b}}$ & $\overline{M I C}$ & MBC & $\overline{M I C}$ & MBC & $\overline{\mathrm{MIC}}$ & MBC \\
\hline Streptococcus mutans DSM 20523 & 78 & 156 & 19.5 & 39 & 1250 & 1250 & 6.00 & 25.00 \\
\hline Streptococcus sobrinus DSM 20381 & 39 & 1250 & 19.5 & 39 & 1250 & 1250 & 10.00 & 15.00 \\
\hline Streptococcus oralis ATCC 35037 & 39 & 78 & 19.5 & 78 & 1250 & 1250 & 10.00 & 10.00 \\
\hline Enterococcus faecalis ATCC 29212 & 156 & 1250 & 78 & 312 & 1250 & 1250 & 15.00 & 25.00 \\
\hline Candida albicans DSM 1386 & 1250 & 1250 & 1250 & 1250 & 1250 & 1250 & 8.00 & 8.00 \\
\hline Escherichia coli ATCC 25922 & 1250 & 1250 & 1250 & 1250 & 1250 & 1250 & 10.00 & 10.00 \\
\hline Staphylococcus aureus ATCC 25923 & 1250 & 1250 & 78 & 1250 & 1250 & 1250 & 10.00 & 25.00 \\
\hline Porphyromonas gingivalis W381 & 2.4 & 9.8 & 9.8 & 9.8 & 625 & 1250 & 12.50 & 12.50 \\
\hline Prevotella intermedia ATCC 25611 & NA & NA & NA & NA & NA & NA & $3.12(5 d)$ & 3.12 \\
\hline Fusobacterium nucleatum ATCC 25586 & 625 & 625 & 625 & 625 & 1250 & 1250 & 6.25 & 6.25 \\
\hline Parvimonas micra ATCC 23195 & 2.4 & 9.8 & 625 & 1250 & 1250 & 1250 & $6.25(5 d)$ & 12.50 \\
\hline
\end{tabular}

NA No activity observed: MIC or MBC were measured at $1250 \mu \mathrm{g} \mathrm{mL}^{-1}, 5 \mathrm{~d}=$ values yielded after 5 days of incubation, ${ }^{a} \mathrm{MIC}=$ extract concentration at which the optical density (OD) measurement revealed minimal bacterial growth, ${ }^{\mathrm{b}} \mathrm{MBC}=$ extract concentration at which a three log reduction (99.9\%) of the bacterial growth was induced

concentrations in the range of $9.8-25 \mu \mathrm{g} \mathrm{mL}{ }^{-1}$, against oral streptococci and anaerobic pathogenic bacteria such as Porphyromonas gingivalis, Fusobacterium nucleatum and Parvimonas micra. These results confirm the findings of a previous report, which also provided evidence of the high antimicrobial potential of maslinic acid (MIC $=15-30 \mu \mathrm{g} \mathrm{mL}^{-1} ; \quad \mathrm{MBC}=25-50 \mu \mathrm{g} \mathrm{mL}^{-1}$ ) against S. aureus, E. coli, E. faecalis and Pseudomonas aeruginosa [41]. Maslinic acid belongs to natural pentacyclic triterpenoids, which are able to damage the cell envelope of both Gram-positive and Gram-negative bacteria [42]. Furthermore, carbon-associated $\mathrm{R}$ stereochemistry within this organic compound and the production of synthetic maslinic acid derivatives with the presence of sulfur and chlorine atoms and extra hydroxyl group seem to enhance its antimicrobial capacity [41]. In another report, maslinic acid demonstrated improved antibacterial effects $\left(0.9 \mu \mathrm{g} \mathrm{mL}^{-1}\right)$ compared to the antibiotic kanamycin $\left(0.9 \mu \mathrm{g} \mathrm{mL}^{-1}\right)$ toward the Gram-positive Bacillus thuringiensis and a substantial inhibitory activity against the Gram-negative E. coli, Salmonella enterica and Shigella dysenteria [43]. Nevertheless, maslinic acid failed to eradicate Gram-negative bacteria such as E. coli, P. aeruginosa and Klebsiella pneumoniae in an earlier study [44]. In addition to its inhibitory effect, maslinic acid has proven antioxidant, antitumor and antidiabetogenic activity [45].

The other three compounds isolated from O. europaea, namely oleuropein, oleocanthal, hydroxytyrosol and oleacein presented more moderate inhibitory effects compared to maslinic acid against the Gram-negative anaerobic $P$. gingivalis and $F$. nucleatum. Oleuropein is a oleosidic ester of 3,4-dihydroxyphenylethanol [46] isolated from olive leaves. Indeed, there are many reports on the high-level antibacterial activity of oleuropein using various microorganisms [47-49]. Recently, Bisignano et al. highlighted also the antibacterial action of an oleuropein derivative, namely 3,4-DHPEA-EA, against Gram-positive ATCC strains, food and clinical isolates of Staphylococcus epidermidis and S. aureus [50]. One possible mechanism of action involves the prevention of the activity repression of lactoperoxidase mediated by hydrogen peroxide $\left(\mathrm{H}_{2} \mathrm{O}_{2}\right)$. As a result, the increased release of its oxidation product named hypothiocyanite $\left({ }^{-} \mathrm{OSCN}\right)$, which can penetrate microbial biofilms, leads to enhanced bacteriostatic features $[51,52]$. Interestingly, to strengthen its antibacterial behavior lactic acid bacteria such as Lactobacillus plantarum are able to hydrolyze and subsequently convert oleuropein into hydroxytyrosol [53]. The phenolic compound hydroxytyrosol was most effective against Gram-negative anaerobic bacteria. This fact is of high importance in oral infections, since Gram negative bacteria such as $P$. gingivalis are associated with periodontal disease while Gram positive microorganisms correlate with periodontal health [54]. In a previous study, 4-hydroxytyrosol also exerted bactericidal activity against the Gram-positive $S$. aureus as well as the virulent staphylococcal enterotoxin A [55]. The antibacterial behavior of hydroxytyrosol $\left(400 \mu \mathrm{g} \mathrm{mL}^{-1}\right)$ and the combination hydroxytyrosol/gallic acid against E. coli, Klebsiella pneumoniae, Streptococcus pyogenes and S. aureus was confirmed in another recent report [56].

Oleocanthal and oleacein constitute two aldehydic compounds of olive oil with great structural similarity [57]. To date, both substances have proven to be natural non-steroidal, antioxidant and anti-inflammatory 
compounds $[58,59]$. Scotece et al. elucidated the active anti-inflammatory role of oleocanthal [60]. In particular, oleocanthal interferes with the activity of lipopolysaccharide (LPS)-stimulated macrophages and chondrocytes hindering nitric oxide (NO), interleukin (IL-6, IL-1 $\beta$ ) and tumor necrosis factor $\alpha$ (TNF- $\alpha)$ production [60]. Oleacein was documented to protect the cardiovascular system by decreasing the progression of atherosclerosis and repairing angiotensin II-affected endothelial progenitor cells [59, 61]. With regard to its antibacterial traits, the present study is the first report on the moderate, yet effective inhibitory activity of oleocanthal and oleacein, especially against anaerobic oral pathogens. However, oleanonic aldehyde as well as the other tested extracts proved to be ineffective against the anerobic $P$. intermedia.

Among all tested triterpenoid acids, oleanolic acid was the most active natural pentacyclic triterpenoid (MIC, $\mathrm{MBC}=9.8 \mu \mathrm{g} \mathrm{mL}^{-1}-1.25 \mathrm{mg} / \mathrm{mL}^{-1}$ ) of $P$. lentiscus. The tree provides a resinous exudate named mastic gum [62]. With reference to the biological behavior of oleanolic acid, it seems to beneficially modulate the peroxisome proliferator-activated receptors (PPAR) which are activated in several diseases e.g. diabetes mellitus, dyslipidemia and metabolic syndrome [63]. In a recent microbiological study, oleanolic acid synergized with the ß-lactam antibiotics ampicillin and oxacillin against the Gram-positive S. aureus, S. epidermidis and Listeria monocytogenes [42]. This can be attributed to the inhibition of the release of $\beta$-lactamase, allowing for the easier eradication of methicillin-resistant $S$. aureus by ß-lactams [64]. Nevertheless, Shin et al. showed that oleanolic acid can act solely in synergy with aminoglycoside antibiotics such as kanamycin and cannot enhance the effectiveness of other antimicrobial agents e.g. tetracycline, norfloxacin and rifampicin against Acinetobacter baumannii. In that case the possible mechanism of action involves alteration in energy metabolism pathways and cell membrane susceptibility [65]. Another report underlined the superior inhibitory effects of oleanolic acid (MIC $=30 \mu \mathrm{g} \mathrm{mL}^{-1}-80 \mu \mathrm{g} \mathrm{mL} \mathrm{m}^{-1}$ compared to several triterpene acids against oral streptococci and E. faecalis [66]. Interestingly, it seems that the interference of oleanolic acid with cell envelope, the structure and location of the acyl group on ring A results in a wide-spectrum antimicrobial action against Gram-positive and Gram-negative microorganisms $[41,42]$. This was also confirmed in an earlier report on a novel pentacyclic triterpene, namely 3-oxoolean-12(13),18(19)-dien-29 $\alpha$-carboxylic acid [67].

The natural tetracyclic triterpenoid 24Z-isomasticadienolic acid showed an enhanced inhibitory activity compared to oleanonic aldehyde against Gram-positive and Gram-positive anaerobic oral pathogens as well as streptococci. 24Z-isomasticadienolic acid has proven to possess anti-inflammatory traits against acute and chronic infections. In particular, 24Z-isomasticadienolic acid completely abolished the release of leukotriene B4 $\left(\mathrm{LTB}_{4}\right)$ from polymorphonuclear leukocytes [68]. 24Z-isomasticadienolic $(\mathrm{MBC}=0.2 \mathrm{mg} / \mathrm{ml})$ and it exerted significant antibacterial effects against Helicobacter pylori strains $(\mathrm{MBC}=0.35 \mathrm{mg} / \mathrm{ml})$ [37]. Since there are no available data on the antimicrobial properties of oleanonic aldehyde, a pentacyclic triterpene, the current study contains the first promising results against oral bacteria.

\section{Conclusions}

In conclusion, the present study highlighted the high-level antimicrobial efficacy of eight different constituents of $O$. europaea and $P$. lentiscus against a panel of nine different oral microorganisms. Overall, compounds from $O$. europaea and $P$. lentiscus such as maslinic acid and oleanolic acid were extremely effective against the tested oral pathogens, especially streptococci and anaerobic oral microorganisms. All tested extracts proved to be ineffective against the anerobic $P$. intermedia. Thus, future clinical studies should investigate the use of these natural antimicrobial agents in the treatment of caries- and periodontitis-related oral biofilms.

\begin{abstract}
Abbreviations
Avr: Avirulence; CBA: Columbia blood agar plates; CC: Column chromatography; $\mathrm{CFU}$ : Colony forming units; $\mathrm{CH}_{2} \mathrm{Cl}_{2}$ : Dichloromethane; cHex: Cyclohexane; CHX: Chlorhexidine; CLSI: Clinical and Laboratory Standards Institute; DMSO: Dimethyl sulfoxide; EfaA: Endocarditis-related antigen $\mathrm{A}$; EtOH: Ethanol; EVOO: Extra virgin olive oil; $\mathrm{H}_{2} \mathrm{O}$ : Water; $\mathrm{HCB}$ : Yeastcysteine blood agar plates; HPLC: High performance liquid chromatography; IL: Interleukin; MBC: Minimum bactericidal concentration; MeOH: Methanol; MHB: Mueller-Hinton Broth; MIC: Minimum inhibitory concentration; MPLC: Medium pressure liquid chromatography; MS: Mass spectrometry; MW: Molecular weight; NMR: Nuclear magnetic resonance spectroscopy; NO: Nitric oxide; - OSCN: Hypothiocyanite; PPAR: Peroxisome proliferatoractivated receptors; SDB: Sabouraud Dextrose Broth; Si: Silica; TLC: Thin layer chromatography; TMEWP: Total mastic extract without polymer; TNFa: Tumor necrosis factor a; UV: Ultraviolet; WCB: Wilkins-Chalgren broth
\end{abstract}

\section{Acknowledgments}

Not applicable.

\section{Funding}

This study was supported in part by the German Research Foundation (DFG, AL 1179/2-1). This funding body was not involved in the design of the study or collection, analysis, or interpretation of data or in writing the manuscript.

\section{Availability of data and materials}

The datasets used and/or analysed during the current study are available from the corresponding author on reasonable request.

\section{Authors' contributions}

LK, AAA conceived the idea for this report; LK and AA were involved in the data analysis, wrote and critically reviewed the manuscript; MC, AW participated in the study design and conducted the assays; EH, AS and JT read and critically reviewed the manuscript. All authors read and approved the final manuscript.

Ethics approval and consent to participate Not applicable.

Consent for publication

Not applicable. 


\section{Competing interests}

The authors declare that they have no competing interests.

\section{Publisher's Note}

Springer Nature remains neutral with regard to jurisdictional claims in published maps and institutional affiliations.

\section{Author details}

Clinic for Preventive Dentistry, Periodontology and Cariology, Center of Dental Medicine, University of Zurich, Zürich, Switzerland. ${ }^{2}$ Department of Operative Dentistry and Periodontology, Medical Center, Faculty of Medicine, University of Freiburg, Freiburg, Germany. ${ }^{3}$ Department of Pharmacognosy and Natural Products Chemistry, Faculty of Pharmacy, National and Kapodistrian University of Athens, Athens, Greece. ${ }^{4}$ PharmaGnose S.A Papathanasiou 24, 34100 Chalkida, Euboea, Greece. Institute of Medical Microbiology and Hygiene, Faculty of Medicine, University of Freiburg, Freiburg, Germany. ${ }^{6}$ Department of Operative Dentistry, Periodontology and Endodontology, University of Dental Medicine and Oral Health, Danube Private University (DPU), Krems, Austria.

Received: 21 November 2017 Accepted: 18 February 2019 Published online: 26 February 2019

\section{References}

1. Newman DJ, Cragg GM. Natural products as sources of new drugs from 1981 to 2014. J Nat Prod. 2016;79(3):629-61.

2. Sofrata A, Santangelo EM, Azeem M, Borg-Karlson AK, Gustafsson A, Putsep K. Benzyl isothiocyanate, a major component from the roots of Salvadora persica is highly active against gram-negative bacteria. PLoS One. 2011;6(8):e23045.

3. Ngo LT, Okogun Jl, Folk WR. 21st century natural product research and drug development and traditional medicines. Nat Prod Rep. 2013;30(4):584-92.

4. Takebe Y, Saucedo CJ, Lund G, Uenishi R, Hase S, Tsuchiura T, Kneteman N, Ramessar K, Tyrrell DL, Shirakura M, et al. Antiviral lectins from red and bluegreen algae show potent in vitro and in vivo activity against hepatitis $C$ virus. PLoS One. 2013;8(5):e64449.

5. Wahba NM, Ahmed AS, Ebraheim ZZ. Antimicrobial effects of pepper, parsley, and dill and their roles in the microbiological quality enhancement of traditional Egyptian Kareish cheese. Foodborne Pathog Dis. 2010;7(4):411-8.

6. Petrolini FV, Lucarini R, de Souza MG, Pires $\mathrm{RH}$, Cunha WR, Martins $\mathrm{CH}$. Evaluation of the antibacterial potential of Petroselinum crispum and Rosmarinus officinalis against bacteria that cause urinary tract infections. Braz J Microbiol. 2013;44(3):829-34.

7. Fournomiti M, Kimbaris A, Mantzourani I, Plessas S, Theodoridou I, Papaemmanouil V, Kapsiotis I, Panopoulou M, Stavropoulou E, Bezirtzoglou $\mathrm{EE}$, et al. Antimicrobial activity of essential oils of cultivated oregano (Origanum vulgare), sage (Salvia officinalis), and thyme (Thymus vulgaris) against clinical isolates of Escherichia coli, Klebsiella oxytoca, and Klebsiella pneumoniae. Microb Ecol Health Dis. 2015;26:23289.

8. Alvin A, Miller Kl, Neilan BA. Exploring the potential of endophytes from medicinal plants as sources of antimycobacterial compounds. Microbiol Res. 2014:169(7-8):483-95.

9. Tiwari V, Roy R, Tiwari M. Antimicrobial active herbal compounds against Acinetobacter baumannii and other pathogens. Front Microbiol. 2015;6:618.

10. Gonzalez-Lamothe R, Mitchell G, Gattuso M, Diarra MS, Malouin F, Bouarab K. Plant antimicrobial agents and their effects on plant and human pathogens. Int J Mol Sci. 2009;10(8):3400-19.

11. Ng TB, Ye XJ, Wong JH, Fang EF, Chan YS, Pan W, Ye XY, Sze SC, Zhang KY, Liu F, et al. Glyceollin, a soybean phytoalexin with medicinal properties. Appl Microbiol Biotechnol. 2011;90(1):59-68.

12. Ahuja I, Kissen R, Bones AM. Phytoalexins in defense against pathogens. Trends Plant Sci. 2012;17(2):73-90

13. Dangl $\mathrm{J}$, Jones JD. Plant pathogens and integrated defence responses to infection. Nature. 2001:411(6839):826-33.

14. Maor R, Shirasu K. The arms race continues: battle strategies between plants and fungal pathogens. Curr Opin Microbiol. 2005;8(4):399-404.

15. Abedinzadeh M, Gaeini M, Sardari S. Natural antimicrobial peptides against Mycobacterium tuberculosis. J Antimicrob Chemother. 2015;70(5):1285-9.

16. Hoffmann AR, Proctor LM, Surette MG, Suchodolski JS. The microbiome: the trillions of microorganisms that maintain health and cause disease in humans and companion animals. Vet Pathol. 2015;53(1):10-21.
17. Blekhman R, Goodrich JK, Huang K, Sun Q, Bukowski R, Bell JT, Spector TD, Keinan A, Ley RE, Gevers D, et al. Host genetic variation impacts microbiome composition across human body sites. Genome Biol. 2015;16:191.

18. Ding T, Schloss PD. Dynamics and associations of microbial community types across the human body. Nature. 2014;509(7500):357-60.

19. Battin TJ, Sloan WT, Kjelleberg S, Daims H, Head IM, Curtis TP, Eberl L. Microbial landscapes: new paths to biofilm research. Nat Rev Microbiol. 2007;5(1):76-81.

20. Filoche $\mathrm{S}$, Wong $\mathrm{L}$, Sissons $\mathrm{CH}$. Oral biofilms: emerging concepts in microbial ecology. J Dent Res. 2010;89(1):8-18.

21. Beikler T, Flemmig TF. Oral biofilm-associated diseases: trends and implications for quality of life, systemic health and expenditures. Periodontol 2000. 2011;55(1):87-103.

22. Karygianni L, Ruf S, Follo M, Hellwig E, Bucher M, Anderson AC, Vach K, AlAhmad A. Novel broad-Spectrum antimicrobial Photoinactivation of in situ Oral biofilms by visible light plus water-filtered infrared a. Appl Environ Microbiol. 2014:80(23):7324-36

23. Al-Ahmad A, Ameen H, Pelz K, Karygianni L, Wittmer A, Anderson AC, Spitzmuller B, Hellwig E. Antibiotic resistance and capacity for biofilm formation of different bacteria isolated from endodontic infections associated with root-filled teeth. J Endod. 2014;40(2):223-30.

24. Ioannidis I, Sakellari D, Spala A, Arsenakis M, Konstantinidis A. Prevalence of tetM, tetQ, nim and Bla(TEM) genes in the oral cavities of Greek subjects: a pilot study. J Clin Periodontol. 2009:36(7):569-74.

25. Jeon JG, Rosalen PL, Falsetta ML, Koo H. Natural products in caries research: current (limited) knowledge, challenges and future perspective. Caries Res. 2011;45(3):243-63.

26. Chandra Shekar BR, Nagarajappa R, Suma S, Thakur R. Herbal extracts in oral health care - a review of the current scenario and its future needs. Pharmacogn Rev. 2015;9(18):87-92

27. Radulovic NS, Blagojevic PD, Stojanovic-Radic ZZ, Stojanovic NM. Antimicrobial plant metabolites: structural diversity and mechanism of action. Curr Med Chem. 2013:20(7):932-52.

28. Yang C, Chowdhury MA, Huo Y, Gong J. Phytogenic compounds as alternatives to in-feed antibiotics: potentials and challenges in application. Pathogens. 2015;4(1):137-56

29. Gross EL, Beall CJ, Kutsch SR, Firestone ND, Leys EJ, Griffen AL. Beyond Streptococcus mutans: dental caries onset linked to multiple species by $16 S$ rRNA community analysis. PLoS One. 2012;7(10):e47722.

30. Tennert C, Fuhrmann M, Wittmer A, Karygianni L, Altenburger MJ, Pelz K, Hellwig E, Al-Ahmad A. New bacterial composition in primary and persistent/secondary endodontic infections with respect to clinical and radiographic findings. J Endod. 2014;40(5):670-7.

31. Brito F, Zaltman C, Carvalho AT, Fischer RG, Persson R, Gustafsson A, Figueredo CM. Subgingival microflora in inflammatory bowel disease patients with untreated periodontitis. Eur J Gastroenterol Hepatol. 2013;25(2):239-45.

32. Gasparoto TH, Dionisio TJ, de Oliveira CE, Porto VC, Gelani V, Santos CF, Campanelli AP, Lara VS. Isolation of Candida dubliniensis from denture wearers. J Med Microbiol. 2009;58(Pt 7):959-62.

33. Karygianni L, Cecere M, Skaltsounis AL, Argyropoulou A, Hellwig E, Aligiannis N, Wittmer A. High-level antimicrobial efficacy of representative Mediterranean natural plant extracts against oral microorganisms. Biomed Res Int. 2014;2014:839019.

34. Xynos N, Abatis D, Argyropoulou A, Polychronopoulos P, Aligiannis N, Skaltsounis AL. Development of a sustainable procedure for the recovery of Hydroxytyrosol from table olive processing wastewater using adsorption resin technology and centrifugal partition chromatography. Planta Med. 2015;81(17):1621-7.

35. Keiler AM, Zierau O, Bernhardt R, Scharnweber D, Lemonakis N, Termetzi A, Skaltsounis L, Vollmer G, Halabalaki M. Impact of a functionalized olive oil extract on the uterus and the bone in a model of postmenopausal osteoporosis. Eur J Nutr. 2014;53(4):1073-81.

36. Vulcano I, Halabalaki M, Skaltsounis L, Ganzera M. Quantitative analysis of pungent and anti-inflammatory phenolic compounds in olive oil by capillary electrophoresis. Food Chem. 2015;169:381-6.

37. Paraschos S, Magiatis $P$, Mitakou S, Petraki K, Kalliaropoulos A, Maragkoudakis $P$, Mentis A, Sgouras D, Skaltsounis AL. In vitro and in vivo activities of Chios mastic gum extracts and constituents against helicobacter pylori. Antimicrob Agents Chemother. 2007;51(2):551-9.

38. Barton DHR, Seoane E. Triterpenoids. Part XXII. The constitution and stereochemistry of masticadienonic acid. J Chem Soc. 1956;189:4150-7.

39. NCCLS, National Committee for Clinical Laboratory Standards vol. vol. Wayne, PA, USA; 1999 
40. NCCLS, National Committee for Clinical Laboratory Standards vol. Approved Standard M7-A6, 6th edition edn. edn. Villanova, PA, USA; 2003.

41. Chouaib K, Hichri F, Nguir A, Daami-Remadi M, Elie N, Touboul D, Ben Jannet $H$, Hamza MA. Semi-synthesis of new antimicrobial esters from the natural oleanolic and maslinic acids. Food Chem. 2015;183:8-17.

42. Kurek A, Nadkowska P, Pliszka S, Wolska Kl. Modulation of antibiotic resistance in bacterial pathogens by oleanolic acid and ursolic acid. Phytomedicine. 2012;19(6):515-9.

43. Wang J, Ren H, Xu QL, Zhou ZY, Wu P, Wei XY, Cao Y, Chen XX, Tan JW. Antibacterial oleanane-type triterpenoids from pericarps of Akebia trifoliata. Food Chem. 2015;168:623-9.

44. Braca A, Morelli I, Mendez J, Battinelli L, Braghiroli L, Mazzanti G. Antimicrobial triterpenoids from Licania heteromorpha. Planta Med. 2000; 66(8):768-9

45. Rufino-Palomares EE, Reyes-Zurita FJ, Garcia-Salquero L, Mokhtari K, Medina PP, Lupianez JA, Peragon J. Maslinic acid, a triterpenic anti-tumoural agent, interferes with cytoskeleton protein expression in HT29 human coloncancer cells. J Proteome. 2013;83:15-25.

46. Barbaro B, Toietta G, Maggio R, Arciello M, Tarocchi M, Galli A, Balsano C. Effects of the olive-derived polyphenol oleuropein on human health. Int J Mol Sci. 2014;15(10):18508-24.

47. Lee $\mathrm{OH}$, Lee BY. Antioxidant and antimicrobial activities of individual and combined phenolics in Olea europaea leaf extract. Bioresour Technol. 2010; 101(10):3751-4.

48. Saavedra MJ, Borges A, Dias C, Aires A, Bennett RN, Rosa ES, Simoes M Antimicrobial activity of phenolics and glucosinolate hydrolysis products and their synergy with streptomycin against pathogenic bacteria. Med Chem. 2010;6(3):174-83.

49. Waterman E, Lockwood B. Active components and clinical applications of olive oil. Altern Med Rev. 2007;12(4):331-42.

50. Bisignano C, Filocamo A, Ginestra G, Giofre SV, Navarra M, Romeo R, Mandalari G. 3,4-DHPEA-EA from Olea europaea $L$. is effective against standard and clinical isolates of Staphylococcus sp. Ann Clin Microbiol Antimicrob. 2014;13:24.

51. Flemmig J, Rusch D, Czerwinska ME, Rauwald HW, Arnhold J. Components of a standardised olive leaf dry extract (Ph. Eur.) promote hypothiocyanite production by lactoperoxidase. Arch Biochem Biophys. 2014;549:17-25.

52. Chandler JD, Day BJ. Thiocyanate: a potentially useful therapeutic agent with host defense and antioxidant properties. Biochem Pharmacol. 2012; 84(11):1381-7.

53. Santos MM, Piccirillo C, Castro PM, Kalogerakis N, Pintado ME. Bioconversion of oleuropein to hydroxytyrosol by lactic acid bacteria. World J Microbiol Biotechnol. 2012;28(6):2435-40.

54. Dabdoub SM, Tsigarida AA, Kumar PS. Patient-specific analysis of periodontal and peri-implant microbiomes. J Dent Res. 2013;92(12 Suppl): $168 s-75 s$.

55. Friedman M, Rasooly R, Do PM, Henika PR. The olive compound 4hydroxytyrosol inactivates Staphylococcus aureus bacteria and staphylococcal enterotoxin a (SEA). J Food Sci. 2011;76(8):M558-63.

56. Tafesh A, Najami N, Jadoun J, Halahlih F, Riepl H, Azaizeh H. Synergistic antibacterial effects of polyphenolic compounds from olive mill wastewater. Evid Based Complement Alternat Med. 2011;2011:431021

57. Vougogiannopoulou K, Lemus C, Halabalaki M, Pergola C, Werz O, Smith AB 3rd, Michel S, Skaltsounis L, Deguin B. One-step semisynthesis of oleacein and the determination as a 5-lipoxygenase inhibitor. J Nat Prod. 2014;77(3):441-5.

58. Smith AB 3rd, Han Q, Breslin PA, Beauchamp GK. Synthesis and assignment of absolute configuration of (-)-oleocanthal: a potent, naturally occurring non-steroidal anti-inflammatory and anti-oxidant agent derived from extra virgin olive oils. Org Lett. 2005;7(22):5075-8.

59. Naruszewicz M, Czerwinska ME, Kiss AK. Oleacein. Translation from Mediterranean diet to potential antiatherosclerotic drug. Curr Pharm Des. 2015;21(9):1205-12.

60. Scotece M, Gomez R, Conde J, Lopez V, Gomez-Reino JJ, Lago F, Smith AB 3rd, Gualillo O. Further evidence for the anti-inflammatory activity of oleocanthal: inhibition of MIP-1alpha and IL-6 in J774 macrophages and in ATDC5 chondrocytes. Life Sci. 2012;91(23-24):1229-35.

61. Parzonko A, Czerwinska ME, Kiss AK, Naruszewicz M. Oleuropein and oleacein may restore biological functions of endothelial progenitor cells impaired by angiotensin II via activation of Nrf2/heme oxygenase-1 pathway. Phytomedicine. 2013;20(12):1088-94.
62. Modugno F, Ribechini E, Colombini MP. Chemical study of triterpenoid resinous materials in archaeological findings by means of direct exposure electron ionisation mass spectrometry and gas chromatography/mass spectrometry. Rapid Commun Mass Spectrom. 2006;20(11):1787-800.

63. Georgiadis I, Karatzas T, Korou LM, Katsilambros N, Perrea D. Beneficial health effects of Chios gum mastic and peroxisome proliferator-activated receptors: indications of common mechanisms. J Med Food. 2015;18(1):1-10.

64. Kuroda M, Nagasaki S, Ohta T. Sesquiterpene farnesol inhibits recycling of the C55 lipid carrier of the murein monomer precursor contributing to increased susceptibility to beta-lactams in methicillin-resistant Staphylococcus aureus. J Antimicrob Chemother. 2007:59(3):425-32.

65. Shin B, Park W. Synergistic effect of Oleanolic acid on aminoglycoside antibiotics against Acinetobacter baumannii. PLoS One. 2015;10(9):e0137751.

66. Scalon Cunha LC, Andrade e Silva ML, Cardoso Furtado NA, Vinholis AH, Gomes Martins $\mathrm{CH}$, da Silva Filho AA, Cunha WR. Antibacterial activity of triterpene acids and semi-synthetic derivatives against oral pathogens. Z Naturforsch C. 2007;62(9-10):668-72.

67. Brahmachari G, Mandal NC, Roy R, Ghosh R, Barman S, Sarkar S, Jash SK, Mondal S. A new pentacyclic triterpene with potent antibacterial activity from Limnophila indica Linn. (Druce). Fitoterapia. 2013;90:104-11.

68. Giner-Larza EM, Manez S, Giner RM, Recio MC, Prieto JM, Cerda-Nicolas M, Rios JL. Anti-inflammatory triterpenes from Pistacia terebinthus galls. Planta Med. 2002;68(4):311-5
Ready to submit your research? Choose BMC and benefit from:

- fast, convenient online submission

- thorough peer review by experienced researchers in your field

- rapid publication on acceptance

- support for research data, including large and complex data types

- gold Open Access which fosters wider collaboration and increased citations

- maximum visibility for your research: over $100 \mathrm{M}$ website views per year

At BMC, research is always in progress.

Learn more biomedcentral.com/submissions 